\title{
Validation of the spectrophotometric method for the dosing of some combined capsules
}

\author{
${ }^{* 1,2}$ Livia Uncu, ${ }^{1}$ Vladilena Evtodienco, ${ }^{1}$ Ecaterina Mazur, ${ }^{2}$ Elena Donici, ${ }^{1,2}$ Vladimir Valica
}

${ }^{1}$ Scientific Center for Drug Research, ${ }^{2}$ Department of Pharmaceutical and Toxicological Chemistry

Nicolae Testemitanu State University of Medicine and Pharmacy, Chisinau, the Republic of Moldova

\author{
Authors' ORCID iDs, academic degrees and contributions are available at the end of the article \\ *Corresponding author - Livia Uncu, e-mail: livia.uncu@usmf.md \\ Manuscript received July 22, 2021; revised manuscript October 06, 2021; published online October 12, 2021
}

\begin{abstract}
Background: UV-Vis spectrophotometry remains the most accessible spectral method with a high degree of sensitivity and information. The advantage of the method consists in its universality, the ability to combine with other methods, the minimum error, as well as its economic efficiency. The objective of this study was the determination of some validation parameters for the spectrophotometric method of dosing piracetam and nicergoline in combined capsules.

Material and methods: Agilent $8453 \mathrm{UV}$-Vis spectrophotometer, reference standards of piracetam and nicergoline, $0.1 \mathrm{M} \mathrm{HCl}$ methanolic solution. Validation of the spectrophotometric method according to the requirements of the ICH guide "Q2R1: For analytical procedures and validation".

Results: Linearity was investigated on concentration ranges 5-40 $\mu \mathrm{g} / \mathrm{mL}$. The regression $\left(\mathrm{R}^{2}\right)$ values were 0.9998 for nicergoline and 0.998 for piracetam, respectively. The limit of detection was $1.737 \mu \mathrm{g} / \mathrm{mL}$ for nicergoline and $0.369 \mu \mathrm{g} / \mathrm{mL}$ for piracetam. Quantification limit values were also calculated as 5.265 and $1.118 \mu \mathrm{g} / \mathrm{mL}$ for nicergoline and piracetam, accordingly. The results obtained showed that the developed spectrophotometric method is accurate, precise and robust, because the value of the relative standard deviation was less than $1.0 \%$.

Conclusions: The developed spectrophotometric method showed specificity, linearity, accuracy, precision and robustness, and can be applied on the concentration range between $80-120 \%$ of the nominal value of the content of nicergoline and piracetam in the preparation.

Key words: dosing, UV-Vis spectrophotometry, validation.
\end{abstract}

Cite this article

Uncu L, Evtodienco V, Mazur E, Donici E, Valica V. Validation of the spectrophotometric method for the dosing of some combined capsules. Mold Med J. 2021;64(4):10-16. https://doi.org/10.52418/moldovan-med-j.64-4.21.02.

\section{Introduction}

The combination of the medicinal substances in a single dosage form is a globally recognized practice. Due to the advantages of the fixed-dose combinations (FDCs) which have been shown over time, FDCs are widely applied in the treatment of a large number of pathologies, such as cardiovascular $[1,2]$ and respiratory [3, 4], tuberculosis [5, 6], HIV [7], diabetes [8], pain management [9], infectious diseases [10]. Among the most important advantages are: (a) the improvement of the response rate compared to monotherapy, based on different mechanisms of drug action in the combination; (b) reduced doses and toxicity; (c) achievement of the faster effect by FDC's than monocomponent; (d) better compliance by reducing the pill burden and adherence improvement; (e) low cost and saving of resources for the patients and the health system [11-13]. Most FDCs come in solid dosage forms: tablets and capsules, containing two active ingredients, rarely three and more.

Hard capsules are used as a delivery system for FDCs due to the fact that they are inert and do not interact with drug's components; they can have different sizes, including customized sizes and they are ideal for packaging of hygroscopic substances; the production technology is not complicated; they are convenient for administration [14].

The development of combination drugs includes several specific steps, being a process with many challenges, related to the nature and properties of the active ingredients which can cause incompatibilities, different doses, different pharmacokinetic properties and bioavailability etc. [15]. A major challenge in the development of FDCs is the development of analytical methods for the simultaneous determination of each component of the mixture. Researchers usually opt for physico-chemical methods, which offer the possibility of separating the components, are accurate and sensitive. Numerous factors, such as chemical structure, molecular weight, pKa values, $\mathrm{UV}$ absorption, concentration of active principle in the analyzed sample, solubility of compounds, are taken into account when selecting the method. Chromatographic methods, especially high pressure liquid chromatography (HPLC), are most often used for the analysis of combined products, the working techniques being complex and difficult to perform.

A very important step in the FDCs standardization is the development of the simple, accessible, fast and accurate methods of analysis. UV-Vis spectrophotometry is one of the 
alternatives that can be proposed and meets all the nominated requirements. It is based on the absorption of electromagnetic radiation by molecules of the substances. Therefore, this method can be used successfully for the analysis of compounds with chromophore groups.

Hearing is one of the most important senses of human being, which is the source of sound, being an essential means of communication. Any difficulty in percepting the sound is defined as a hearing loss, pathology with various etiology and pathophysiological mechanisms. In neurosensory hypoacuzia, the difficulty of sound reset is determined by dysfunction in the inner ear [16]. Treatment of neurosensory hypoacuzia remains a serious problem. Corticosteroids are indicated as first-line medicines. At the same time, certain emphasis is placed on the advancement of the hemodynamics in the region of the innear ear, the improvement of the metabolism, the blood rheology and the stimulation of the auditory analyzer. The medical treatment includes several types of medicines: vasodilators, nutrients, anti-inflammatories, antioxidants. Medicines, in particular, vinpocetine, pentoxifylline, cerebrolysin, piracetam are given in the first days parenterally, then orally $[17,18]$. The concomitant use of several medicines in treatment regimens for hearing loss justifies efforts to develop combined medicines, which would solve several pharmacotherapeutic problems of this disease. Thus, research was carried out at the Scientific Center for Drug Research (SCDR) in order to develop an original composition containing nicergoline, piracetam and Hawthorn dry extract in the one dosage form - capsules.

Nicergoline (fig. 1) is an analogue of ergot alkaloids, which associates in the molecule a nucleus of hydrogenated lysergic acid and nicotinic acid, belongs to the alpha-adrenolytics group, possesses vasodilating action. Due to the presence of nicotinic acid in its structure, it manifests direct spasmolytic myotropic action on the vessels muscles, increases their permeability for glucose. Nicergoline acts predominantly on the cerebral vessels and lower and upper limbs, improves cerebral, pulmonary and renal blood circulation [19].

Piracetam (fig. 1) is a cyclized derivative of gamma-aminobutyric acid, with nootropic action, intensifies energy and plastic processes in the brain, has the ability to restore the structure of cell membranes, the three-dimensional structure of membrane and transmembrane proteins, with the recovery of their functionality [20].
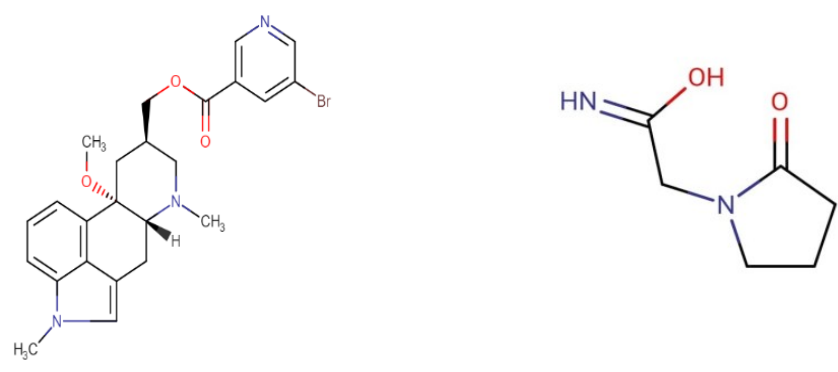

Fig. 1. The chemical structures of nicergoline (left) [21] and piracetam (right) [22]
Data from the literature provide information on several methods applied in bulk nicergoline analysis, in one-component forms or various combinations: HPLC [23], spectrofluorimetry [24, 25], spectrophotometry [26]. Chromatographic [27-29] and spectral [30, 31] methods are also reported for piracetam. It should be noted that the simultaneous determination of these two substances has not been reported, since they are associated for the first time in the same pharmaceutical form.

The purpose of this study was to develop and validate a simple, accurate and reproducible UV-Vis spectrophotometric technique to analyze nicergoline in combination with piracetam in capsules.

\section{Material and methods}

The experimental researches were carried out at the Laboratory of elaboration, analysis, standardization and control of medicines (LEASCM) of the SCDR within Nicolae Testemitanu State University of Medicine and Pharmacy.

The elaboration of the assay method of combined capsules was performed based on the requirements of the ICH guideline "Q2R1: For analytical and validation procedures" [32].

Three experimental series of laboratory-prepared operculated capsules containing nicergoline, piracetam, Hawthorn dry extract and excipients were used in the studies.

Apparatus

The Agilent Technologies 8453 Spectrophotometer equipped with $10 \mathrm{~mm}$ matched quartz cells was used.

Substances, solvents and reagents

Reference standards of nicergoline and piracetam (Sigma Aldrich), methanol (MeOH, Sigma Aldrich), hydrochloric acid ( $\mathrm{HCl}) 0,1 \mathrm{M}$ were used.

Preparation of the standard solutions

$0.05 \mathrm{~g}$ of standard piracetam was transferred into a $25 \mathrm{~mL}$ volumetric flask, was dissolved in $0.1 \mathrm{M} \mathrm{HCl}$ methanol solution and then adjusted up to the mark with the same diluent. $1.2 \mathrm{~mL}$ of the obtained solution was transferred into a $25 \mathrm{~mL}$ volumetric flask and adjusted up to the mark with the same diluent (dil.1). After that, $2.5 \mathrm{ml}$ of obtained solution was diluted to $10 \mathrm{~mL}$ with the same diluent (dil.2).

$0.005 \mathrm{~g}$ of standard nicergoline was transferred into a 25 $\mathrm{mL}$ volumetric flask, dissolved in $0.1 \mathrm{M} \mathrm{HCl}$ methanol solution and adjusted up to the mark with the same diluent. Then, $5.0 \mathrm{~mL}$ of obtained solution was transferred into a 25 $\mathrm{mL}$ volumetric flask and volume was adjusted up to the mark with the same diluent (dil.1). After that, $2.5 \mathrm{ml}$ of obtained solution was diluted to $10 \mathrm{~mL}$ with the same diluent (dil.2).

Preparation of the sample solutions

A content weight of one capsule was taken into a $50 \mathrm{~mL}$ volumetric flask, then $40 \mathrm{~mL}$ of $0.1 \mathrm{M} \mathrm{HCl}$ methanol solution was added and shaken well until it dissolved. After that, the obtained solution was filtered and made up to the mark with the same diluent (stock solution). For the analysis of piracetam, $0.6 \mathrm{~mL}$ of stock solution was withdrawn and taken into a $50 \mathrm{~mL}$ volumetric flask. The volume was adjusted up to mark with the same diluent (dil.1). Then, $5 \mathrm{~mL}$ of obtained 
solution was diluted to $10 \mathrm{~mL}$ with the same diluent (dil.2). For the analysis of nicergoline, $10.0 \mathrm{~mL}$ of stock solution was withdrawn and taken into a $25 \mathrm{~mL}$ volumetric flask. The volume was adjusted with the same diluent up to mark (dil.1). Then, $5 \mathrm{~mL}$ of obtained solution was diluted to $10 \mathrm{~mL}$ with the same diluent (dil.2).

\section{Preparation of placebo solutions}

Accurately weighed Hawthorn dry extract and excipients were calculated for one capsule and were taken into a $50 \mathrm{~mL}$ volumetric flask. Then, $40 \mathrm{~mL}$ of $0.1 \mathrm{M} \mathrm{HCl}$ methanol solution was added and shaken well until it dissolved. After that, the obtained solution was filtered and made up to the mark with the same diluent (placebo solution). For the analysis of piracetam, $0.6 \mathrm{~mL}$ of placebo solution was withdrawn and taken into a $50 \mathrm{~mL}$ volumetric flask. The volume was adjusted up to mark with the same diluent (dil.1). Then, $5 \mathrm{~mL}$ of obtained solution was diluted to $10 \mathrm{~mL}$ with the same diluent (dil.2). For the analysis of nicergoline, $10.0 \mathrm{~mL}$ of placebo solution was withdrawn and taken into a $25 \mathrm{~mL}$ volumetric flask. The volume was adjusted up to mark with the same diluent (dil.1). Then, $5 \mathrm{~mL}$ of obtained solution was diluted to $10 \mathrm{~mL}$ with the same diluent (dil.2).

\section{Quantitative determination}

The absorbance of standard and sample solutions was measured using $10 \mathrm{~mm}$ matched quartz cells and $0.1 \mathrm{M} \mathrm{HCl}$ methanol solution as reference solution.

The quantitative content of nicergoline and piracetam in capsules was determined by using Eq. (1):

$$
X, g=\frac{A_{a n}{ }^{*} m_{s t}{ }^{*} W_{a n}{ }^{*} P}{A_{s t}{ }^{*} m_{a n}{ }^{*} W_{s t}}
$$

$\mathrm{A}_{\mathrm{an}}$ - absorbance of the sample solutions;

$\mathrm{A}_{\text {st }}$ - absorbance of the standard solutions;

$\mathrm{M}_{\mathrm{an}}$ - mass of the sample substance, $\mathrm{g}$;

$\mathrm{m}_{\mathrm{st}}$ - mass of the standard substance, $\mathrm{g}$;

$P$ - average content mass of one capsule;

$W_{s t}$ and $W_{a n}$ - the volumes of dilution for standard and sample solutions respectively.

\section{Validation of the method}

According to the ICH guide the method was validated for parameters, such as linearity, accuracy, precision, sensitivity (LOQ and LOD) and robustness, selectivity, solution stability [32].

The linearity of the spectrophotometric method of assay of piracetam and nicergoline was investigated in the concentration range from $5-40 \mu \mathrm{g} / \mathrm{mL}$. Thus, standard stock solutions of substances were prepared: 5 samples with different concentrations of piracetam and nicergoline of 5, 10, $24,30,40 \mu \mathrm{g} / \mathrm{mL}$ and $5,10,15,20,30 \mu \mathrm{g} / \mathrm{mL}$, respectively. The determinations were performed in triplicate, being constructed the calibration curve (fig. 2). Linear regression analysis was used to evaluate the linearity of the calibration curve using the least squares method.

The selectivity of the spectrophotometric method of assay of piracetam and nicergoline was investigated by measuring the absorbance of the placebo solutions at the spectrophoto- meter using the $10 \mathrm{~mm}$ matched quartz cells in the wavelength range $200-350 \mathrm{~nm}$. 0.1 M HCl methanol solution was used as the reference solution.

Determination of the accuracy of the method was prepared using three samples consisting of nicergoline, piracetam and a mixture of excipients in $0.1 \mathrm{M} \mathrm{HCl}$ methanol solution at concentration levels of $80-120 \%$ of the stated amount, with 3 replicates for each concentration. The percentage recovery of the amount of substance and \% RSD were calculated for each of the replicate samples (tab. 1).

The nicergoline and piracetam concentrations were determined using the calibration curve, and the percentage of regression has been established by using Eq. (2).

$$
\mathrm{R}=\left[\left(\mathrm{C}_{\mathrm{t}}-\mathrm{C}_{\mathrm{p}}\right) / \mathrm{C}_{\mathrm{a}}\right]^{\star} 100 \% \text {, where: }
$$

$\mathrm{R}$ - recovery, \%;

$\mathrm{C}_{t}$ - concentration of the sample with the addition, $\mu \mathrm{g} / \mathrm{mL}$;

$\mathrm{C}_{\mathrm{p}}$ - sample concentration without addition, $\mu \mathrm{g} / \mathrm{mL}$;

$\mathrm{C}_{\mathrm{a}}$ - concentration of the standard with the addition, $\mu \mathrm{g} / \mathrm{mL}$.

Determination of precision of the method was performed by evaluating repeatability and intermediate precision [33]. Repeatability was determined using six samples of capsules, which were analyzed on the same day and under the same conditions. Intermediate precision was determined using six samples of capsules, which were analyzed in different days over the period of a week by different analysts (tab. 2). The concentration of nicergoline and piracetam from capsules was determined.

The sensitivity of the method was investigated by determining the limit of detection (LOD) and limit of quantification (LOQ) by analyzing the substance solutions and measuring the signal-to-noise ratio. LOD is the concentration, which is due to the signal/noise ratio of about 3:1, while LOQ is the concentration that gives a signal/noise ratio of about 10:1 with RSD values $(n=3)$ less than $10 \%$.

The robustness of the method was investigated by varying the maximum absorption wavelength of nicergoline and piracetam with $\pm 2 \mathrm{~nm}$ [32]. The determinations were repeated 3 times at each wavelength (tab. 3).

The stability of standard and sample solutions was determined by analyzing them immediately after preparation and after 24 hours at room temperature $\left(25^{\circ} \mathrm{C}\right)$. Three determinations were performed, the absorbance was evaluated, the concentrations of analyte in the samples (relative to a freshly prepared reference solution) and the $\%$ RSD were calculated (tab. 4).

\section{Statistical analysis}

Statistical analysis was carried out by using the Statistical Package for the Social Sciences (IBM SPSS Statistics) 10.5 software.

\section{Results and discussion}

The piracetam and nicergoline standard solutions showed absorption maxima at $205 \mathrm{~nm}$ and $287 \mathrm{~nm}$, respectively. The same maxima were detected on the spectrum of the sample solution. The spectrum of the placebo solution showed a very low absorption at $272 \mathrm{~nm}$ (fig. 2). 

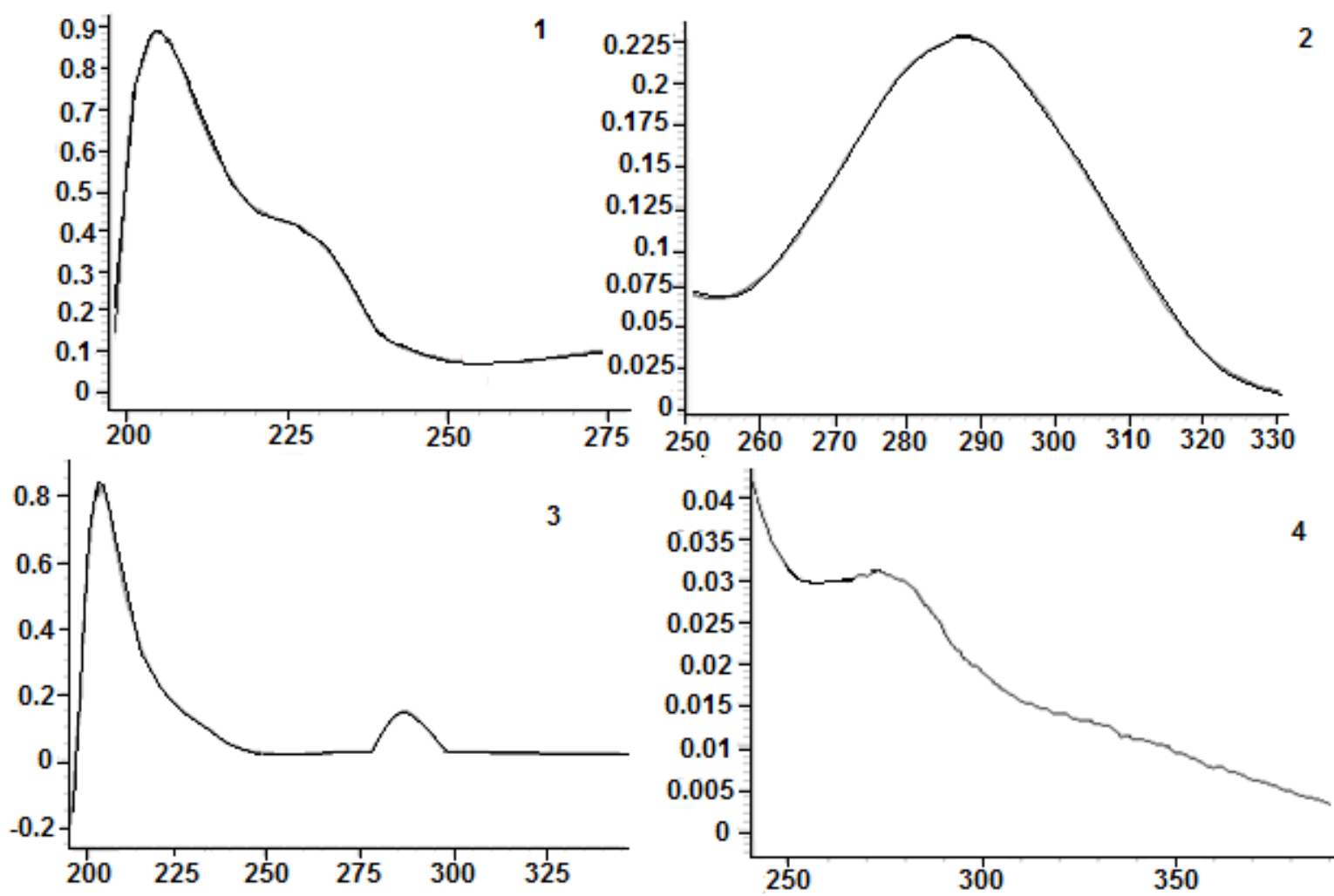

Fig. 2. Absorption spectra of standard piracetam (1) and nicergoline (2), sample (3) and placebo (4) solutions in $0.1 \mathrm{M} \mathrm{HCl}$ methanol solution
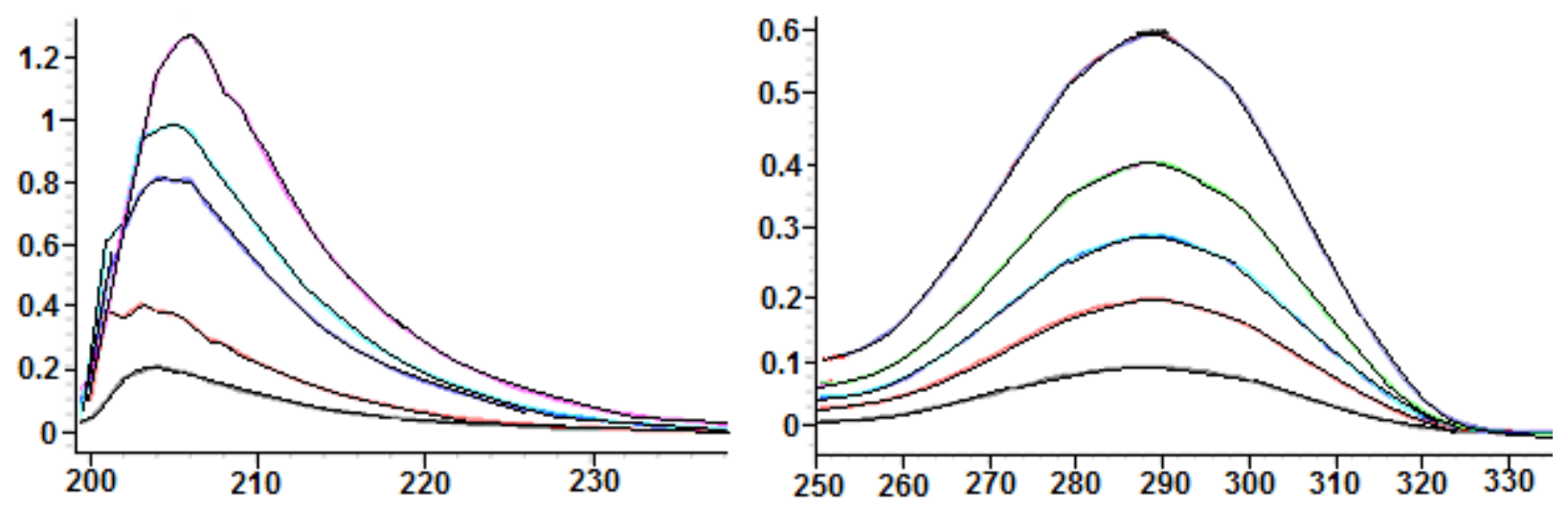

Fig. 3. Absorption spectra of piracetam (left) and nicergoline (right) standard solutions for linearity

The validation of the method was carried out in accordance with the ICH Guide "Q2R1: For Analytical Procedures and Validation" [32].

The linearity of the UV-Vis spectrophotometric method was determined in the concentration range of $5-40 \mu \mathrm{g} / \mathrm{mL}$ of piracetam and $5-30 \mu \mathrm{g} / \mathrm{mL}$ of nicergoline. Based on the obtained results, the calibration curve was drawn and the equation of linear regression was obtained (fig. 3 and 4).

The obtained results showed a linear regression of the method in the concentration range between $5-40 \mu \mathrm{g} / \mathrm{mL}$ of piracetam and $5-30 \mu \mathrm{g} / \mathrm{mL}$ of nicergoline. 

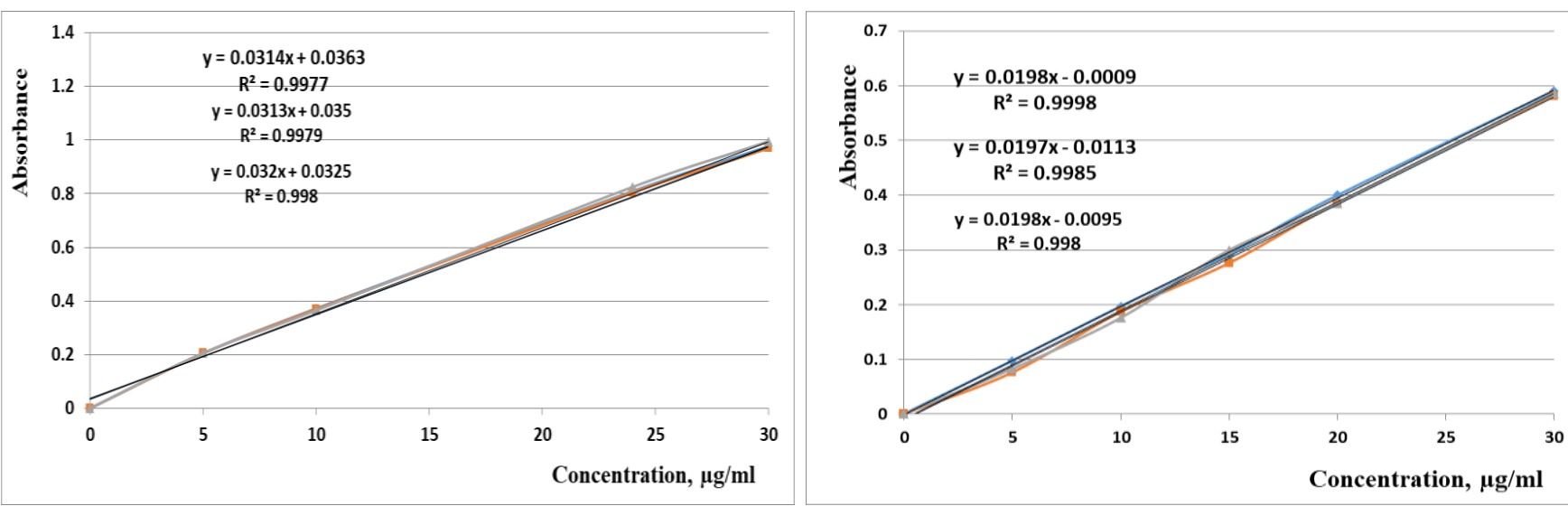

Fig. 4. Calibration curves of standard solutions of piracetam (left) and nicergoline (right) ( $n=3$ determinations)

The values of $L O D$ calculated in accordance with the ICH guide were $1.737 \mu \mathrm{g} / \mathrm{mL}$ for nicergoline and $0.369 \mu \mathrm{g} / \mathrm{mL}$ for piracetam [32].

The values of $L O Q$ calculated in accordance with the ICH guide were also calculated as 5.265 and $1.118 \mu \mathrm{g} / \mathrm{mL}$ for nicergoline and piracetam, respectively [32].

The method is selective, as placebo solution showed a very low absorption at the wavelength $(272 \mathrm{~nm})$ different from the absorption peaks of nicergoline and piracetam. Also, Hawthorn dry extract and excipients did not influence the results of the determinations.
Accuracy is expressed as the percentage of recovered analytes compared to actual values (tab. 1). The admissibility condition is at least $99 \%$ [32].

The developed UV-Vis spectrophotometric method for the assay of nicergoline and piracetam from combined capsules, is accurate, with an average recovery value ranging from $99.8 \%$ to $101.8 \%$. RSD values were between 0.11 $0.69 \%$, as indicated in tab. 1 .

Precision is generally expressed by standard deviation and standard relative deviation. As a result of studies the average values of substance concentrations were calculated after 6 determinations for each 3 capsule series (tab. 2).

Table 1. Recovery as a condition of admissibility

\begin{tabular}{|c|c|c|c|c|c|c|c|c|c|}
\hline \multirow[t]{3}{*}{ Nr. } & \multicolumn{4}{|c|}{$\begin{array}{l}\text { The amount of Ciprofloxacin hydrochloride taken } \\
\text { into work }\end{array}$} & \multirow{2}{*}{\multicolumn{2}{|c|}{$\begin{array}{c}\text { Amount of Ciprofloxacin } \\
\text { hydrochloride }(\mathrm{mg} / \mathrm{mL} \text { ) } \\
\text { (average for } \mathrm{n}=3 \text { ) }\end{array}$}} & \multirow{2}{*}{\multicolumn{2}{|c|}{$\begin{array}{c}\text { Recovery } \\
(\%)\end{array}$}} & \multirow{3}{*}{$\begin{array}{c}\text { RSD } \\
(\%) \\
\text { N/P }\end{array}$} \\
\hline & \multicolumn{2}{|c|}{ (\%) } & \multicolumn{2}{|c|}{$(\mathrm{mg} / \mathrm{mL})$} & & & & & \\
\hline & $\mathrm{N}$ & $P$ & $\mathrm{~N}$ & $P$ & $\mathrm{~N}$ & $P$ & $\mathrm{~N}$ & $P$ & \\
\hline 1 & 80 & 80 & 8.0 & 8.0 & 7.94 & 8.05 & 99.21 & 101.78 & $0.69 / 0.53$ \\
\hline 2 & 100 & 100 & 10.0 & 10.0 & 10.04 & 9.99 & 100.73 & 99.80 & $0.19 / 0.11$ \\
\hline 3 & 120 & 120 & 12.0 & 12.0 & 11.99 & 12.01 & 99.95 & 100.15 & $0.23 / 0.54$ \\
\hline
\end{tabular}

Note: $\mathrm{N}$ - Nicergoline, P - Piracetam, RSD - Relative standard deviation.

Table 2. Results of the repeatability determination and intermediate precision for piracetam and nicergoline in combinated capsules

\begin{tabular}{|c|c|c|c|c|c|c|c|c|c|c|c|c|}
\hline \multirow{3}{*}{$\begin{array}{c}\text { Parameters } \\
\text { Substances } \\
\text { Series }\end{array}$} & \multicolumn{6}{|c|}{ Repeatability: C, g } & \multicolumn{6}{|c|}{ Intermediate precision: $\mathrm{C}, \mathrm{g}$} \\
\hline & \multicolumn{3}{|c|}{ P } & \multicolumn{3}{|c|}{$\mathrm{N}$} & \multicolumn{3}{|c|}{$\mathbf{P}$} & \multicolumn{3}{|c|}{$\mathrm{N}$} \\
\hline & S 01 & S 02 & S 03 & S 01 & S 02 & S 03 & S 01 & S 02 & S 03 & S 01 & S 02 & S 03 \\
\hline 1 & 0.2010 & 0.2001 & 0.2001 & 0.0046 & 0.0046 & 0.0046 & 0.2000 & 0.1997 & 0.2000 & 0.0046 & 0.0046 & 0.0046 \\
\hline 2 & 0.2005 & 0.2001 & 0.2003 & 0.0045 & 0.0045 & 0.0046 & 0.2003 & 0.1997 & 0.1999 & 0.0045 & 0.0046 & 0.0046 \\
\hline 3 & 0.2006 & 0.2004 & 0.2001 & 0.0046 & 0.0046 & 0.0045 & 0.2013 & 0.1999 & 0.2001 & 0.0045 & 0.0046 & 0.0045 \\
\hline 4 & 0.2004 & 0.2006 & 0.2003 & 0.0046 & 0.0046 & 0.0045 & 0.1997 & 0.1994 & 0.1997 & 0.0045 & 0.0045 & 0.0045 \\
\hline 5 & 0.1999 & 0.2004 & 0.2003 & 0.0045 & 0.0045 & 0.0045 & 0.1997 & 0.1992 & 0.2001 & 0.0045 & 0.0045 & 0.0045 \\
\hline 6 & 0.1999 & 0.2001 & 0.2001 & 0.0046 & 0.0046 & 0.0046 & 0.2000 & 0.1999 & 0.1997 & 0.0045 & 0.0045 & 0.0045 \\
\hline Average & 0.2004 & 0.2003 & 0.2003 & 0.0046 & 0.0046 & 0.0046 & 0.2002 & 0.1997 & 0.1999 & 0.0045 & 0.0046 & 0.0046 \\
\hline RSD, \% & 0.2122 & 0.1049 & 0.0703 & 0.5897 & 0.5160 & 0.8382 & 0.2940 & 0.1450 & 0.0940 & 0.7156 & 0.9528 & 0.7189 \\
\hline
\end{tabular}

Note: $\mathrm{N}$ - Nicergoline, P - Piracetam, RSD - Relative standard deviation. 
Table 3. Results of the robustness by spectrophotometric method for piracetam and nicergoline in combined capsules

\begin{tabular}{|c|c|c|c|c|c|c|}
\hline & \multicolumn{3}{|c|}{$P$} & \multicolumn{2}{c|}{ N } & $282 \mathrm{~nm}$ \\
\hline$\lambda, \mathrm{nm}$ & $203 \mathrm{~nm}$ & $205 \mathrm{~nm}$ & $207 \mathrm{~nm}$ & $280 \mathrm{~nm}$ & 0.46205 & 0.46201 \\
\hline A & 0.85099 & 0.85247 & 0.85565 & 0.46128 & 0.4627 & 0.46174 \\
\hline A & 0.85114 & 0.85152 & 0.85489 & 0.46119 & 0.46201 & 0.46189 \\
\hline A & 0.85087 & 0.85089 & 0.85546 & 0.46208 & 0.462253333 & 0.46188 \\
\hline RSD, \% & 0.015896 & 0.09339568 & 0.04624122 & 0.10615694 & 0.083794175 & 0.02928845 \\
\hline
\end{tabular}

Note: $\mathrm{N}$ - Nicergoline, P - Piracetam, A - absorbance, RSD - Relative standard deviation.

The results of the determinations showed that the method is accurate within acceptable limits, RSD values were $\leq$ $2 \%$ (between 0.07 and 0.95 ), so, the developed UV-Vis spectrophotometric method is precise.

Robustness is usually fixed to determine, if the results of the determinations will not be influenced by some insignificant variations in the established parameters, respectively, the validity of the analytical process will be maintained constant. The robustness of the developed method was determined by the variation of wavelengths $\pm 2 \mathrm{~nm}$ (tab. 3).

The results obtained showed that the developed spectrophotometric method is robust, the relative standard deviation is less than $1.0 \%$.

The results of the short-term stability were within the acceptance range. Also, the results showed that the samples were stable at room temperature for 24 hours. Acceptance criteria is: RSD $\leq 2 \%$ [34] (tab. 4).

Table 4. Results of the short-term stability determined by the proposed method $(n=6)$

\begin{tabular}{|c|c|c|c|c|}
\hline \multirow{2}{*}{ Nr. } & \multicolumn{3}{|c|}{$\begin{array}{c}\text { Concentration of piracetam and nicergoline from } \\
\text { capsules, } \mathbf{g}\end{array}$} \\
\cline { 2 - 5 } & \multicolumn{2}{|c|}{ Declared } & \multicolumn{2}{c|}{ Found } \\
\hline & $\mathbf{P}$ & $\mathbf{N}$ & $\mathbf{P}$ & $\mathbf{N}$ \\
\hline $\mathbf{1}$ & 0.2000 & 0.0045 & 0.2016 & 0.0046 \\
\hline $\mathbf{2}$ & 0.2000 & 0.0045 & 0.2014 & 0.0045 \\
\hline $\mathbf{3}$ & 0.2000 & 0.0045 & 0.2011 & 0.0046 \\
\hline $\mathbf{4}$ & 0.2000 & 0.0045 & 0.2001 & 0.0046 \\
\hline $\mathbf{5}$ & 0.2000 & 0.0045 & 0.1998 & 0.0045 \\
\hline $\mathbf{6}$ & 0.2000 & 0.0045 & 0.1989 & 0.0046 \\
\hline Average & 0.2000 & 0.0045 & 0.2005 & 0.0046 \\
\hline RSD, \% & & & 0.2016 & 0.5897 \\
\hline
\end{tabular}

Note: N - N icergoline; P - Piracetam; RSD - Relative standard deviation

\section{Conclusions}

For the first time, the UV-Vis spectrophotometric method of concomitant dosing of piracetam and nicergoline in combined capsules was developed and validated. The proposed work technique is simple, accessible, fast, accurate, sensitive and reproductive. The developed spectrophotometric method serves as an alternative to the chromatographic method (HPLC), and can be included in the quality speci- fication for capsules combined with piracetam, nicergoline and Hawthorn dry extract.

\section{References}

1. Putignano D, Orlando V, Monetti VM, et al. Fixed versus free combinations of antihypertensive drugs: analyses of real-world data of persistence with therapy in Italy. Patient Prefer Adherence. 2019;13:1961-1969. doi: 10.2147/PPA.S225444.

2. Ihm SH, Shin J, Park CG, et al. Efficacy of a fixed dose combination of irbesartan and atorvastatin (Rovelito $((\mathrm{R})))$ in Korean adults with hypertension and hypercholesterolemia. Drug Des Devel Ther. 2019;13:633645. doi: 10.2147/DDDT.S191973.

3. Beasley R, Fingleton J, Weatherall M. Restriction of LABA use to combination ICS/LABA inhaler therapy in asthma. Thorax. 2013;68 (2):119-120. doi: 10.1136/thoraxjnl-2012-202483.

4. Tee A, Chow WL, Burke C, et al. Cost-effectiveness of indacaterol/glycopyrronium in comparison with salmeterol/fluticasone combination for patients with moderate-to-severe chronic obstructive pulmonary disease: a LANTERN population analysis from Singapore. Singapore Med J. 2018;59(7):383-389. doi: 10.11622/smedj.2018022.

5. World Health Organization. Guidelines for treatment of drug-susceptible tuberculosis and patient care, 2017 update [Internet]. Geneva: WHO; 2017 [cited 2021 Jul 2]. Available from: https://apps.who.int/iris/bitstream/handle/10665/255052/9789241550000-eng.pdf

6. Lima GC, Silva EV, Magalhães P, et al. Efficacy and safety of a four-drug fixed-dose combination regimen versus separate drugs for treatment of pulmonary tuberculosis: a systematic review and meta-analysis. Braz J Microbiol. 2017;48(2):198-207. doi: 10.1016/j.bjm.2016.12.003.

7. Mutemwa M, Peer N, de Villiers A, et al. Prevalence, detection, treatment, and control of hypertension in human immunodeficiency virus (HIV)infected patients attending HIV clinics in the Western Cape Province, South Africa. Medicine (Baltimore). 2018;97(35):e12121. doi: 10.1097/ MD.0000000000012121.

8. Jain RK. Empagliflozin/linagliptin single-pill combination therapy for patients with type 2 diabetes mellitus. Expert Opin Pharmacother. 2017;18(6):545-549. doi: 10.1080/14656566.2017.1299712.

9. Daniels SE, Atkinson HC, Stanescu I, et al. Analgesic efficacy of an acetaminophen/ibuprofen fixed-dose combination in moderate to severe postoperative dental pain: a randomized, double-blind, parallelgroup, placebo-controlled trial. Clin Ther. 2018;40(10):1765-76.e5. doi: 10.1016/j.clinthera.2018.08.019.

10. Banek K, Webb EL, Smith SJ, et al. Adherence to treatment with artemether-lumefantrine or amodiaquine-artesunate for uncomplicated malaria in children in Sierra Leone: a randomized trial. Malar J. 2018;17(1):222. doi: 10.1186/s12936-018-2370-x.

11. European Medicines Agency. Guideline on clinical development of fixed combination medicinal products. London: EMA; 2017 [cited 2021 Jul 2]. Available from: https://www.ema.europa.eu/en/documents/ scientific-guideline/guideline-clinical-development-fixed-combinationmedicinal-products-revision-2_en.pdf 
12. Clarke PM, Avery AB. Evaluating the costs and benefits of using combination therapies. Med J Aust. 2014;200(9):518-20. doi: 10.5694/ mja14.00199.

13. Llibre JM, de Lazzari E, Molina JM, et al. Cost-effectiveness of initial antiretroviral treatment administered as single vs multiple tablet regimens with the same or different components. Enferm Infecc Microbiol Clin. 2018;36(1):16-20. doi: 10.1016/j.eimc.2016.07.006.

14. Diez F, Kalafat J, Bhat J. Fixed dose combinations in capsules. Contract Pharma [Internet]. 2019 June 3 [cited 2021 Jul 6]. Available from: https:// www.contractpharma.com/issues/2019-03-01/view_features/fixed-dosecombinations-in-capsules/

15. Hens B, Corsetti M, Bermejo M, Löbenberg R, González PM, Mitra A, Aceituno A. "Development of Fixed Dose Combination Products" Workshop report: Considerations of gastrointestinal physiology and overall development strategy. AAPS J. 2019;21(4):75. doi: 10.1208/ s12248-019-0346-6.

16. Alshuaib WB, Al-Kandari JM, Hasan SM. Classification of hearing loss. In: Bahmad F, Jr., editor. Update on hearing loss. InTech; 2015. doi: $10.5772 / 61835$.

17. Kuhn M, Heman-Ackah SE, Shaikh JA, Roehm PC. Sudden sensorineural hearing loss: a review of diagnosis, treatment, and prognosis. Trends Amplif. 2011 Sep;15(3):91-105. doi: 10.1177/1084713811408349.

18. Uncu L, Gadîrcă A, Parii S, Vislouh O, Suvorchina O. Medicamente combinate utilizate în tratamentul hipoacuziei neurosenzoriale [Combination drugs used in the treatment of neurosensory hearing loss]. Revista Farmaceutică a Moldovei. 2014;(3-4):52. Romanian.

19. Kiran Kumar K, Venkata Nadh R, Nagoji KEV. Extractive spectrophotometric determination of Nicergoline through ion-pair complexation reaction. Oriental J Chem. 2013;29(1):263-269. doi: 10.13005/ojc/290142.

20. Rahate K, Sivadas A, Sathi A, Sathi K. Development and validation of spectrophotometric methods for simultaneous estimation of citicoline and piracetam in tablet dosage form. J Pharm Bioallied Sci. 2013;5(3):202-207. doi: 10.4103/0975-7406.116818.

21. DrugBank Online. Nicergoline [Internet]. [cited 2021 Jul 6]. Available from: https://go.drugbank.com/drugs/DB00699

22. DrugBank Online. Piracetam [Internet]. [cited 2021 Jul 6]. Available from: https://go.drugbank.com/drugs/DB09210

23. Kiran Kumar K, Venkata Nadh R. Development and validation of HPLC method for the estimation of nicergoline in marketed formulations. Rasayan J Chem. 2011;4(4):885-889.

24. Walash MI, Belal F, El-Enany N, Abdelal A. Second-derivative synchronous fluorescence spectroscopy for the simultaneous determination of cinnarizine and nicergoline in pharmaceutical preparations. J AOAC Int. 2008 Mar-Apr;91(2):349-359.

\section{Authors' ORCID iDs and academic degrees}

Livia Uncu, PharmD, PhD, Associate Professor - https://orcid.org/0000-0003-3453-2243

Vlada Evtodienco, PharmD, Researcer - https://orcid.org/0000-0002-5462-3639

Ecaterina Mazur, PharmD, PhD Applicant - https://orcid.org/0000-0003-0725-8410

Elena Donici, PharmD, PhD, Asisstant Professor - https://orcid.org/0000-0001-6862-7449

Vladimir Valica, PharmD, PhD, Professor - https://orcid.org/0000-0002-1068-5504

\section{Authors' contributions}

LU designed the study; VE, EM conducted the laboratory work and performed the analytical part of the laboratory work; LU, ED interpreted the data; LU drafted, revised and approved the manuscript, VV revised and approved the manuscript.

\section{Funding}

This study was supported by Nicolae Testemitanu State University of Medicine and Pharmacy and the research project "Complex researches for the elaboration of the new autochthonous anti-infectious pharmaceutical products for the optimization of the pharmacotherapy of the dental, oropharyngeal and auricular disorders" - 20.80009.8007.14, offered by the National Agency for Research and Development of the Government of the Republic of Moldova. The authors are independent and take responsibility for the integrity of the data and accuracy of the data analysis.

\section{Ethics approval and consent to participate}

The research was approved by the Research Ethics Committee of Nicolae Testemitanu State University of Medicine and Pharmacy (protocol No 45 of 26.02 .2020 ).

Conflict of Interests

No competing interests were disclosed. (anjali MR, Norouzi P. Rapid and direct spectrofluotion of two dansyl derivatives. Spectrosc Lett. 2010;43(3):226-234. doi:

Zayed SI. Simultaneous determination of cinnarizine and nicergoline sinture using first derivative spectra, first derivative of

Acharya M, Ak J, Garud N. Stability indicating reversed phase-high and piracetam in pharmaceutical dosage form. Asian J Pharm Clin Res. 2016;9(2):292-7 method. J Liq Chromatogr Relat Technol. 2005;28(9):1407-1416. doi $10.1081 /$ jlc-200054893. stability-indicating method. Arabian J Chem. 2017;10:S576-S582. doi 10.1016/j.arabjc.2012.11.003 in levetiracetam in pharmaceuticals and biological fluids: plication in stability studies. BioMed Res Int. 2014;2014:1-8. doi:

El-Adl SM, El-sadek ME, Hasan MH. Determination and validation pharmaceuticals using quantitative nuclear magnetic nance spectroscopy. Analytical Chem Lett. 2017;7(2):271-279. doi ICH Harmonised tripartite guideline Q2(R1). Validation of Analytical cext and Methodogy. In: International Conference on Harfor human use. [cited 2021 Jul 6]. Available from: https://database.ich. org/sites/default/files/Q2\%28R1\%29\%20Guideline.pdf termination in combination ear drops. Chem J Mold. 2019;14(2):56-61 doi: http://dx.doi.org/10.19261/cjm.2019.607.

mick AA, Khandelwal KR, Mhaske DV, Swapnil K. Analytical ethod development and validation for piracetam as bulk and in phar2010;65(9):921-928. doi: 10.1134/S1061934810090066. maceutical formulation. Int J PharmTech Res. 2010;2(1):201-204. 